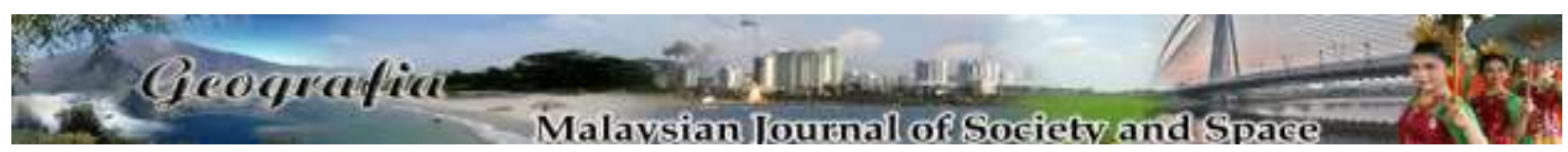

\title{
Indigenous rice: The construction of peasant identities base on cultural ecology
}

\author{
Weeranuch Yamyim ${ }^{1}$, Chusak Wittayapak ${ }^{2}$, Prasit Leepreecha ${ }^{3}$, Charin Mangkhang ${ }^{1}$ \\ ${ }^{1}$ Department of Curriculum, Teaching and Learning, Faculty of Education, \\ Chiang Mai University, Thailand. \\ ${ }^{2}$ Department of Geography, Faculty of Social Science, Chiang Mai University, Thailand. \\ ${ }^{3}$ Department of Social Science and Development, \\ Faculty of Social Science, Chiang Mai University, Thailand.
}

Correspondence: Weeranuch Yamyim (E-Mail: smilesmile_46@hotmail.com)

Received: 22 July 2019; Accepted: 30 June 2020; Published: 28 August 2020

\begin{abstract}
This article studies how peasants have strategies or ways to construct identities through the cultivation of indigenous based on of community cultural ecology. This study used qualitative research methods as a guideline. Field surveys and data collection were conducted with emphasis on observation and group discussion. The result of the study is that peasants' identity is constructed through creating areas for indigenous rice which can be divided into 3 ways; 1) Construction of peasant identities through the ecology of Ban Nam Yen, that is, Ban Nam Yen's indigenous rice is specific to the physical and ecological characteristics of the community as it is suitable for planting in highland areas, hillsides, highland-like crops, grows well in tropical climates, 2) Construction of peasant identities through creating a social space for indigenous rice by presenting indigenous rice to be known through social media, and creating community as agricultural tourism destinations, and 3) Construction of peasant identities through knowledge areas in the community, that is to say, making communities a source of learning both in the systematic learning using the community base for learning and informal learning as learning sources for those interested in field trips. For this reason, the construction of peasant identities is expressed by creating an area through indigenous rice as an instrument in the efforts to maintain the community's identities.
\end{abstract}

Keywords: construction, cultural ecology, identities, indigenous rice, peasant, Thailand

\section{Introduction}

"Thai society is an agricultural society" is a statement that Thai citizens have been aware of since entering the education system from Thai social studies classes of all ages. This is due to 
Thailand having soil, water and air suitable for cultivation of tropical plants. As a result, Thailand has become a food source of the world, especially rice production for consumption and distribution. A major turning point in the Thai rice industry is the policy of opening the country during the reign of King Rama IV in 1855 by the Treaty of Bering with England; it was considered a turning point for Thailand and the peasant society from traditional subsistence production to commercial production (Satsanguan, 2003)

Then the concept of green revolution has changed into modernism under capitalism, and this has transformed the 'peasant' as subsistence producers to become producers of agricultural production. It also construction the changing relationship of countryside structures when it is combined with larger economy, as well as changing relationship between peasant and government to which peasant belong to. Chiengthong (2018) has explained further that the government development policies and the change of peasant society in most developing countries, have important objectives of the country's development-transforming agricultural society into industrial society.

The National Economic and Social Development Plan of Thailand, the first (1961) - seventh (1996) plan, has mentioned the national development plans focusing on industrial and basic infrastructure development such as irrigation for agriculture and transportation system development for transporting cargo, which changed rural areas to become an important part in the primary production sector and forward into the secondary stage- the product processing industry system. Regarding the National Economic and Social Development Plan, the eighth (1997) - twelfth (2021) plan, the focus is on the development of people who are centered on the sufficiency economy and sustainable development because of the consequences from Tom Yum Kung crisis in 1997. However, there was an economic development in terms of increasing productivity on the wisdom of the community, and this economic and social development plan reflects the emphasis on industrial development as the main focus on trade, investment and employment (Office of the National Economic and Social Development Council, 2019).

Sattayanurak (2017) added that changes occurring in peasant society of Thai rural society have construction a new characteristic of rural society. The rural peasant has changed definition of general peasant to agricultural entrepreneurs of the community that is explaining the phenomenon of rural society may not be able to use the traditional feature description framework anymore. Therefore, understanding the changes in rural society is important and urgent because to be aware this rapid and profound change would enable the state and society to appropriately formulate creative policies. If you are not aware, they will become the barriers to effective development and cause the conflicts that should not occur.

From that point, the study of the transformation of a peasant society must be studied together with the study of cultural ecology. In addition, Walliphodom (2013) suggests that the external development process entering the local community caused the change of subsistence production into commercial and export production. This affects the ways of life and cultures, so that some local people are able to adapt oneself and some cannot. This adaptation must be related to the community's ecology, which is considered the first form of capital used to further develop other forms of capital to have value. In addition, country development guidelines focusing on industrial activities have an impact on "Cultural Ecology" of community because all development projects initiated by the government destroy the environment, resources and cultural areas of the local people. In addition, more importantly, the coming of capitalists of multinational corporations who have absolute power to control the decision-making in their careers makes the traditional living of people in the community become vulnerable. There is 
generation gap and migration of new generations to accept innovation that focuses on materialism and economic income.

For this reason, this research present strategies for construction of peasants identities through indigenous rice produced on the base of cultural ecology of community, as cultivation of indigenous rice is considered an indication of the suitability of genetics and local ecosystems. In addition, indigenous rice is a culture which is being affected by the changes in the community economy and changes in the world society. This then causes the indigenous rice to be diminished in value when they have to face with the hybrid rice, monoculture as number one of exportation in Thailand.

\section{Literature review}

The concept of cultural ecology

"Cultural Ecology" is considered part of study in human ecology. In the 1950s, human ecology was known as cultural ecology and is still considered science in the field of geography and anthropology. Wittayapak (2018) explained that;

... " Human ecology and cultural ecology are the same thing which can be used interchangeably. It may be used only in the contexts of different major disciplines, but major concepts are not different "....

Important thinkers of the Cultural Ecology Bureau are such as Carl Sauer and Julian Steward. Sauer (in Wittayapak, 2018) has redefined the geography as a science that understands the landscape and landscape changes due to human activities. It is the study that brings geographic studies to a new way of the cultural landscape studies. An important concept affecting the geographic studies is The Morphology of Landscape in 1965. It is the study that brings geographic studies to a new way of the cultural landscape studies.

In another approach to the study of cultural ecology by Steward, the cultural ecology concept of Steward was known in 1950, about adaptation of traditional society to an existing environment. The important part of this success is the application to study a small and traditional society, especially the society in which the relationship between humans and the environment is relatively stable - stable population and environment. However, this approach cannot be applied well to complex modern societies in relationships and in a situation where the population is large, causing rapid environmental change which necessarily makes the cultural core change at all times.

Research by Zimmerer (2006) presented a work on cultural ecology related to political ecology which is the new geographies of environmental conservation and globalization processes. Cultural ecology is considered similarity of political to geographical ecology and development with a variety of interdisciplinary views. The study presents new and deep information to focus on the expansion of economic geography resulting in the relocation of local people who are often economically disadvantaged and socially disadvantaged individuals. Study of cultural ecology consists of 2 important issues: spatial dimension and environmental dimension. The study of cultural ecology tends to emphasize the awareness of the importance to protect the biodiversity of modern environments, especially cultural ecology and political 
ecology systems, namely globalization that promotes interaction between resource conservation and agricultural subsistence as well as other resource users.

However, if we look at the culture of rice of the issue of food security and cultural security of glutinous rice, Sattaka, et al. (2017) has raised the case study of Vietnam, as their top priority in the Mekong sub-region and due to physical fertility, agriculture is main occupation of the people, especially small peasant who still use traditional indigenous rice and production methods due to related expertise. Regarding the culture of consuming glutinous rice as a main food in Vietnam, there are variety of species and different types of cultivation methods and conservation that should be promoted in a community knowledge management. However, rice cultivation in Vietnam has been focused on various chemicals matter because peasant have a small cultivated area, thus they have to make intensive agriculture in order to produce enough rice for consumption and distribution.

All of these, cultural ecology theory will help answer question about how human society develop specific behavior patterns. This is seen as behavioral systems that is socially conveyed and has a duty to link people in communities to a particular environment. It emphasized cultural system as a behavioral system including technology, economic and political organization, settlement groups, religions, beliefs, practices and values. It is an emphasis on living in the environment that is specific community or society. Cultural ecology concept is a conceptual framework for studying factors that make the community continue to live of rice farming and other occupations as supplementary occupations at the end of the season. Because farming must relate to natural environment and society, so it relies on the relationship among population, the physical and social environmental of the peasant in the communities studied, including to understand the adaptation to changed circumstances right now as well.

\section{Method and Study Area}

This article studied peasant society on how they construct identities and create areas for indigenous rice to be produced based on community cultural ecology. Qualitative research method was used as a guideline for surveying and collecting field data that focus on in-depth interviews, observation, and group discussion. Data collection tools were interview forms, group discussions, and textual analysis data obtained from interviews, observations, group discussions, and activities conducted in the field. The sample group used in the study was specific selection. The total number of members of the group of indigenous rice growers is 35 households from a total of 180 households.

The context of the study area is a case study of the Ban Nam Yen peasant community, Kok Saton Sub-district, Dan Sai District, located on the western border of Loei Province and is part of the northeastern region of Thailand. The reason for choosing the Ban Nam Yen peasant society as the study area is because the Ban Nam Yen peasant society is entering a capitalist economy system through hybrid rice, contract farming and monoculture. All of this causes changes in production areas, seeds, and integrated subsistence production into commercial production. This results in the reduction of the value of local plants, which are considered geographical indications for ecological fertility and the biodiversity of indigenous rice varieties. It causes the disappearance of the culture of indigenous rice cultivation, community identity, genetic heritage and ancestral heritage. After surveying the study area and related researches, it was found that that Ban Nam Yen has genetic diversity of up to 15 indigenous rice varieties (Kotchakot et al., 
2016) in which villagers have conserved according to local wisdom. However, in the production year 2018, peasants chose to grow only 3 varieties of indigenous rice, i.e. Siw Glian, Luem Pua, and Lueang Boonma.

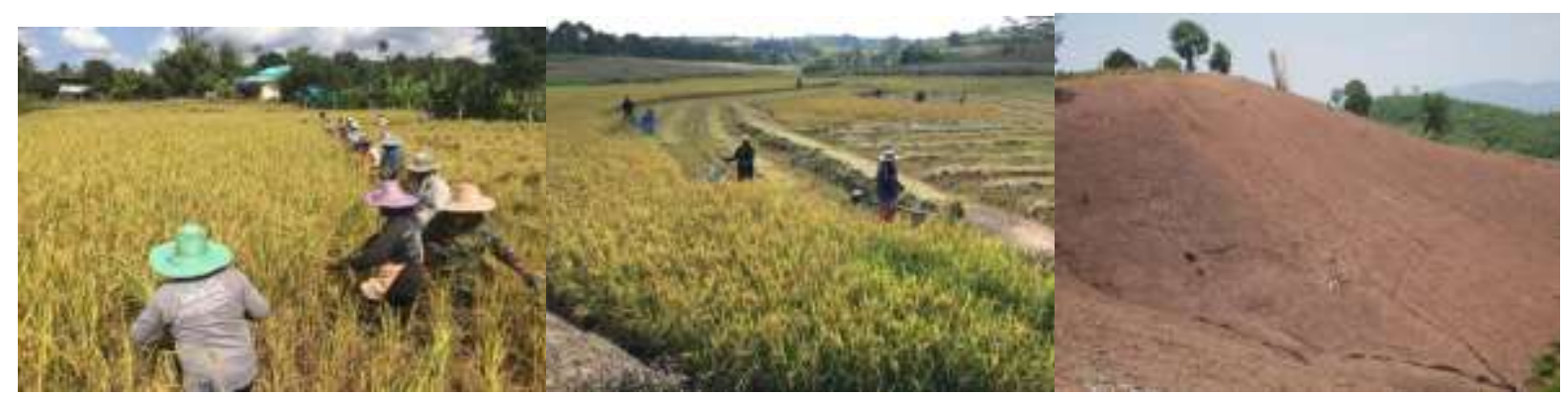

Source: from field survey 2018 recorded by researchers

Figure 1. Indigenous rice harvesting, small size agricultural machinery, improvement of rice varieties and characteristics of indigenous rice planting areas

\section{Results and Discussion}

In the situation of Thai indigenous rice varieties, the Department of Rice tried to create alternatives for consumers by creating and supporting a niche market focusing on organic rice, high nutritional value of rice, and certified rice for geographical indications. This is to add value, make a difference to the hybrid rice, and make choices for consumers about ensuring safety. However, the problem is that this special group of rice is high cost due to the production process and production costs resulting in impossibility to penetrate the consumer market in all groups, and as a result, rice in the niche market is not widely known. This is one of the reasons that indigenous rice has been reduced. The results of this study are divided into 3 issues as follows:

\section{Construction of the peasant identities through the ecology of Ban Nam Yen}

Ban Nam Yen has a total area of approximately 13,550 rai, divided into forest areas of 7,300 rai (59.87\% of the total area), agricultural area 6,220, lowland rice area 456 rai, lowland rice area 5,306 rai, perennial plants area 273 rai, residential area 110 rai, other area 185 Rai. This shows that most of the land is in the National Reserved Forest (Dan Sai District of Agricultural Extension Office, 2015)

Once considering the geographic information of the community through processing with a map showing the location of the study area (Figure 2), the physical characteristics of this study area show that Ban Nam Yen has physical characteristics as a flat area with a high land area in some places. Also, it is surrounded by high to very high ground. Importantly, Phu Pha Phueng in Phu Khi Thao National Forest Reserve in Loei Province has a height between 720-1,080 meters. Phu Pha Phueng is an important food source of Ban Nam Yen which is to find forest products, collect wild mushrooms, and seasonal local mushrooms that are considered to generate income for the community every year. Phu Lom Lo in the Phu Hin Rong Kla National Park is a joint between Loei Province and Phitsanulok Province with a height between 1,440-1,800 meters. It is considered an important tourist destination of Loei province during the months of December to February, being the Unseen Thailand Tourism sponsored by the Tourism Authority of Thailand. 


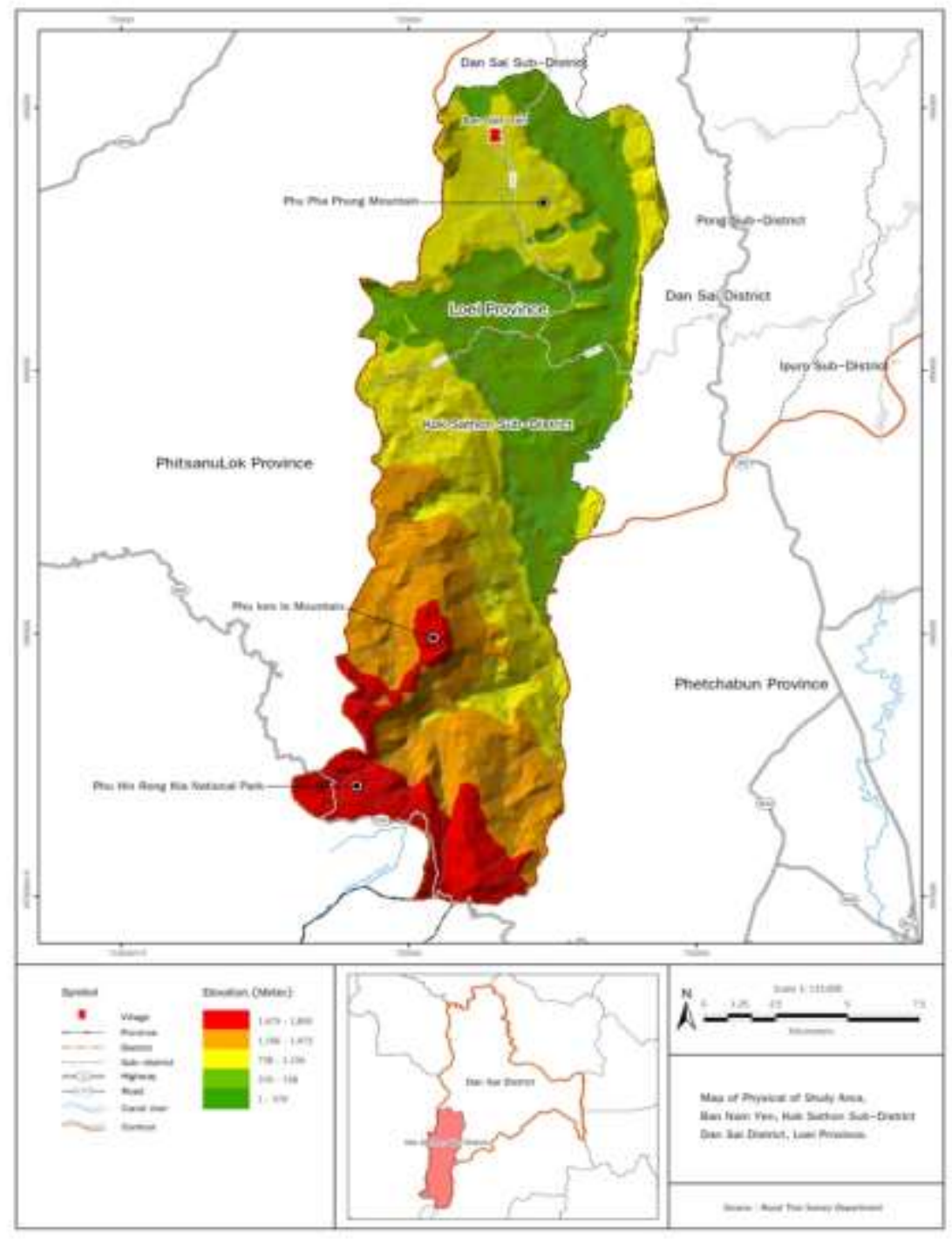

Source: Basic information from the Regional Center for Space Technology and Geographic Information (Northern), Department of Geography, Department Faculty of Social Sciences, Chiang Mai University

Figure 2. Study Area Map

As for soil suitability, there are 3 groups of soil characteristics; 1) suitable for perennials, rubber, 2) suitable for watersheds, and 3) suitable for sugarcane, corn, beans. Furthermore, the soil units at 27, 29 and 62 are suitable for growing crops and fruit trees because the soil is sandy loam, most of which has rock fragments in the lower layers and is steep hills with the slope more than $35 \%$.

The reason that arable land or physical area is important to peasants as they are capital resources with importance for their occupation and indigenous rice varieties. Because the physical characteristics of Ban Nam Yen are steep in some areas, it then makes it suitable for growing up land rice because it is a plant that does not require care, like other plants, does not need water to nourish, use only seasonal rainwater. Peasants have to prepare planting land in May or June and harvest in October or November. The average duration of cultivation is 5-6 
months. Indigenous rice of Ban Nam Yen grows well in a tropical ecological landscape and responds to climate instability because they are outside the main irrigation system. However, if a small slope or lowland area is suitable for growing monoculture and hybrid rice because they have water reserves for agriculture, it would cause indigenous rice to be abolished. Moreover, Ban Nam Yen is in a forest reserve and a national park, causing peasants to not be able to expand their arable land. Unfortunately, Ban Nam Yen's indigenous rice has not been certified as a geographical indication as other rice varieties. Currently, there are 9 rice varieties registered in Geographical Indication in Thailand: Thung Kula Rong Hai Jasmine Rice, Surin Jasmine Rice, Sangyod Muang Phatthalung Rice, Jek Choei Sao Hai, Khao Wong Kalasin Sticky Rice, Khao Hang Hom Thong Sakon Thawapi, Khao Kam Lanna Rice, Lueang Pathio Chumphon Rice, and Khao Rai Luem Phua Phetchabun Rice (Rice Department, 2012). Furthermore, community leader explained the characteristics of indigenous rice as follows (interview);

... Indigenous Rice do not need to invest a lot, because after planting is released naturally. When it was time to harvest, we came to clear the grass and then harvest. This indigenous rice species, insects or aphids will not destroy. And this native rice species is a kind of glutinous rice that is suitable for the culture of Isan people. "...

Nowadays, there are 2 types of indigenous rice varieties of Ban Nam Yen: upland rice planted on the hillside and lowland rice planted in lowland areas. Both types of rice are glutinous rice because the food culture of the communities in the north and northeast of Thailand is sticky rice and cooking suitable for eating sticky rice. The problem found is that the upland rice has decreased in cultivating because peasants share their land for planting other plants such as pineapples, passion fruit, ginger, pepper, as this group of crops can harvest the produce twice a year. This is therefore more worthwhile than planting rice that is harvested once a year and is not in the interest of the market. In addition, the area for rice cultivation that requires flat land or stepped rice fields, peasants have also changed the production of varieties from indigenous rice to hybrid rice, because there are short stalks, easy to harvest, does not require a lot of labor. It therefore saves time and costs.

In this way, it causes community leader to request cooperation from members to share upland fields and lowland fields to conserve and protect varieties and continue processing products for commercial purposes. The members of the indigenous rice group cooperated well by sharing the fields of about 5 rai per household ( 2 acres/household) to grow indigenous rice and the rest of the land planted with monoculture to bring income to the livelihood of the family. From this point, we see that construction of a physical area for the cultivation of indigenous rice varieties is highly fragile due to monoculture, hybrid rice, income, and returns as indicators of change.

In addition, Ban Nam Yen's indigenous rice is similar to Bario rice in Sarawak (Slow Food Foundation for Biodiversity, online), which is organic rice with traditional production methods, non-toxic, mainly uses skills and human labor in cultivation. Differently, Bario rice in Sarawak was registered as a geographical indication and was similar to the cultivation of indigenous rice in Vietnam (Sattaka et al., 2017) where small farmers have food culture of glutinous rice as a staple food. It therefore has various traditional varieties and a variety of cultivation and conservation approaches that need to be promoted in knowledge management of the community. However, globalization has made peasants interested in the use of chemical devices, because small farmers have small plantations, so they have to cultivate intensively in order to get enough 
produce for consumption and distribution. Therefore, this causes them to change rice varieties in cultivation that affect the indigenous rice.

\section{Construction of peasant identities through creating a social space for indigenous rice}

Indigenous rice groups have the objectives of preserving indigenous rice, protecting seed rights as a tool to guarantee food security in the community, and it is also a group to generate income for indigenous rice to gain market share. Ban Nam Yen's strategies are to establish a group of indigenous rice growing group in the community, participate in indigenous rice groups outside community, create exhibitions, public relations through online media, use social media to present rice in different views, deliver indigenous rice to the contest, develop a learning center for indigenous rice, etc. It could bring trade and investment, as well as information exchange. In addition, it also allows peasants to exchange rice varieties, exchange cultivation knowledge, and adapt the cultivation strategies that help them to improve their products such as below (interview);

... The advantages of indigenous rice, in addition to nutritional value, safety in production as organic rice and the eco-friendly production process, alternative food for health-loving groups, it can also determine the purchase price, distribution price by oneself. In terms of the quality of rice, government officials inspect every year. "....

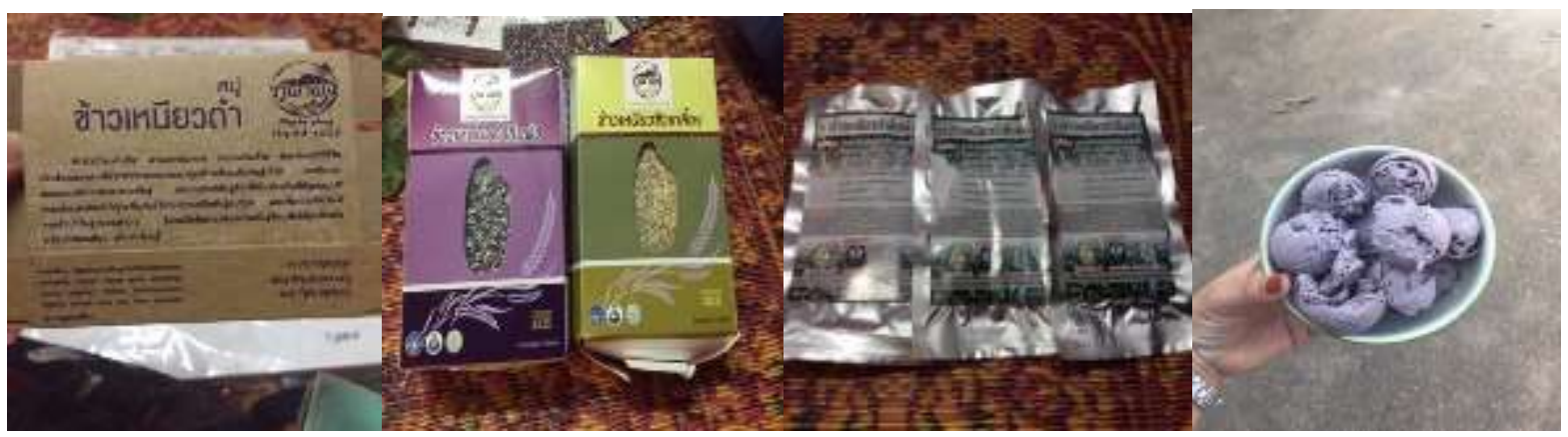

Source: from field survey 2018 recorded by researchers

Figure 3. Processed rice products derived from indigenous rice in Ban Nam Yen on behalf of Phu Pha Phung

The highlights of Ban Nam Yen's indigenous rice, apart from its specification of the physical characteristics of the community, it also relates to the cultural ecology of the community. For example, peasants are preparing fields in May or June and harvest in October or November. The average duration of cultivation is 5-6 months or planting in the rainy season and harvesting in the cold season. It therefore has a culinary culture from newly harvested rice such as Khao Lam Lao from indigenous rice, wild food that people in the community share and talk about their lives of their families and neighbours in the community at the bonfire to relieve the cold. This is creating happiness and socializing in the culture of the countryside.

Furthermore, the important thing of Ban Nam Yen peasant community, besides the way of life that is bound to indigenous rice and local food, there are belief and faith, that is, culture from product of the ecosystem that determines the way of life of the community. In the northeastern 
region of Thailand or Isan, there is an important culture which is 'Heat 12 Khlong 14' (12 Annual Festivals of Isan). Each tradition consists of rice, but in the case of Ban Nam Yen, there is a culture of Boon Khao Plueak (paddy rice culture merit) that reflects the belief and faith in rice that is like the spirit of peasants (considered from the Figure 4) and also reflects the environmental conditions in the community that are conducive to farming career. Especially the variety of indigenous rice varieties is suitable for highland ecosystems.

This culture was created to meet the mental needs of the community to live with the essence of the fortune of the rice that is harvested in that year. This ritual is a wish for peasants to have good products. In addition, rice, fish and food were taken for this ceremony to pay homage to the spirit of ghost farm, Phra Mae Phosop, to help preserve the land, the water to be fertile for the upcoming farming season. In addition, rice is distributed as welfare for households that have elderly people who do not grow rice for consumption and give to the villagers in the community to bring the money for renovation of the temples. At present, indigenous rice has decreased because villagers are interested in growing monoculture. This affects the culture and beliefs of the community because the rice used in the ritual is changed to hybrid rice, and some peasants who do not grow indigenous rice, do not bring rice to make merit. This could make it possible to predict that in the future, Boon Khao Plueak must adapt to respond to peasants' production paths or this culture might gradually disappear.

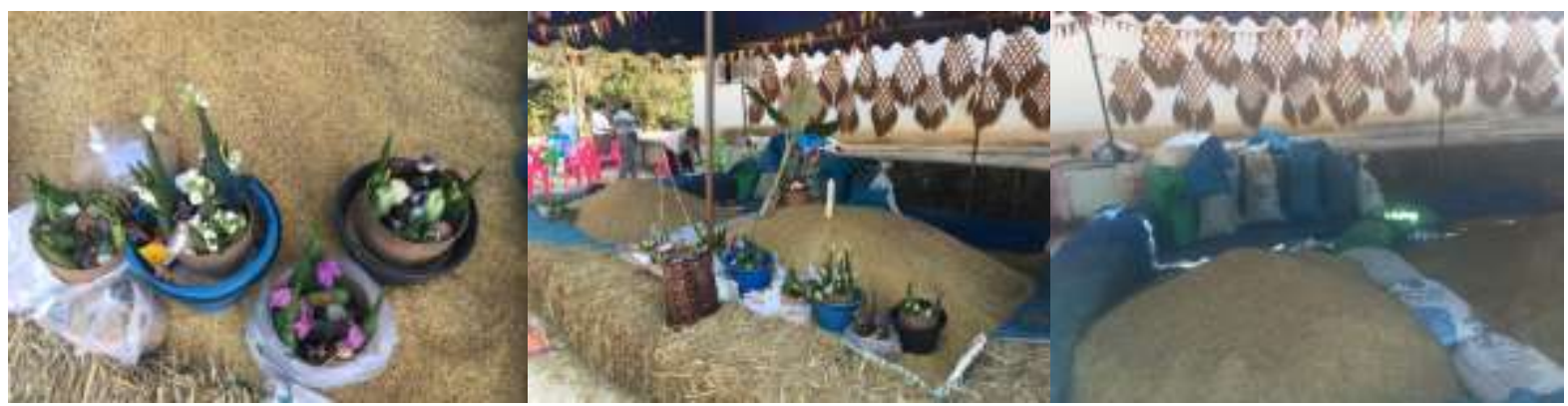

Source: from field survey 2018 recorded by researchers

Figure 4. Boon Khao Plueak or Kwan Khao (Morale of Rice)

\section{Construction of peasant identities through knowledge areas in the community}

In this study, the knowledge areas will be divided into 2 types: knowledge areas in educational institutions and knowledge areas in communities. The knowledge areas in educational institutions have integrated knowledge of indigenous rice with teaching and learning by teaching students to farm rice starting with soil preparation, sowing rice, caring, harvesting and postharvesting. This activity is a guideline for community based learning in education with the reason that strengthening of citizenship requires the youth to know and be aware of their community, because the community is a learning area with a lot of knowledge and experience of people, and local wisdoms to fill the knowledge for them. As the work of Mohd Yusri Ibrahim (2017), youth are important human capital. They will be future leaders that would lead to the country's success. To achieve this goal, young people must be more responsible, accountable, attentive, and more involved in community activities. However, the disadvantage is that youth today is less likely to participate at the community level.

In addition to the knowledge areas in the educational institutions, the community knowledge areas are also considered the significant starting point for self-study and are considered lifelong 
learning. The community learning areas are knowledge area in the form of livelihood, conduct, occupation, learning of the wisdom of the community, beliefs and rituals, and transferring of knowledge by passing on knowledge from generation to generation. This kind of knowledge area is learning from life experiences and practices which enable students to apply, integrate into their careers and livelihoods. Ban Nam Yen has collected all the rice varieties in the community and created a learning source for those interested in studying and using the rice varieties to experiment in cultivation. This is considered the knowledge area of the community that is the conservation area of rice varieties and the practices of the community.

After considering the 3 results of the study together with Lefebvre's space concept (referred in Supanan, 2011), it made us realize that the area is changing, flexible, fluid according to social activities and daily life of humans. Unlike Ban Nam Yen, the contestation is not only in urban society, but also in rural society, such as the contestation of indigenous rice and hybrid rice, the contestation of monoculture and indigenous rice. These are the contestation of spaces through plant genetics and livelihood approaches that result from government policies for agricultural development. The coherence of the study of Lefebvre' (1974) that is the spatial practice or perceived space, in the case of Ban Nam Yen, that are physical space used for living activities: arable land, rice fields, residences, forest areas of community. Representations of space or conceived space in Ban Nam Yen is the perception, imagination of the villagers of the arable land, the meaning of the arable land, beliefs about ghosts in the arable land until creating culture for respecting to the forest spirit, in which this space is a concept of awareness. Spaces of representation or lived spaces are knowledge spaces intended to assimilate the mass of experiences and transfer this knowledge set for conservation and continuation. In this study, Ban Nam Yen Peasant Community is a large area of knowledge, that is, a society of knowledge, wisdom, folk wisdom, learning beyond classroom, and lifelong learning for the general public.

This is in line with the study of Wittayapak (2018), human adaptation to the natural and social environment is to survive under certain conditions. Moreover, it can be said that it is an adaptation to the fundamental problems associated with struggling to live. For Ban Nam Yen villagers, in the past, the environment had a great influence on livelihoods and occupations because they would choose careers in relation to the ecology of the community such as soil, water, climate. Nowadays, the economic system has a great influence on career decisions, causing them to cultivate monoculture without having to worry about the relationship with the environment because of the support by chemicals and labor-saving devices. This has resulted in the decline of indigenous rice and can be analyzed that the definition of cultural ecology in Ban Nam Yen community has a meaning as constantly flowing according to the changing economic conditions because peasants definitely choose livelihood strategies that can cope with problems and survive amidst the limited capital resources and cultural ecology they have with the best interest.

\section{Conclusion}

From the study of peasant society on the issue of how peasants establish strategies or ways of construction of peasant identities through indigenous rice based on the cultural ecology of the community, the answer is the adaptation of peasants to create space for peasants who want to conserve indigenous rice and protect seeds indicating food security of the community, because

indigenous rice is a representative image of the cultural ecology of Ban Nam Yen peasants 
community that can grow in highland ecosystems, can withstand drought and heat, does not need to use chemicals in cultivation, but can produce satisfactory results under the community ecosystem. In addition, it can be said that Ban Nam Yen's indigenous rice is organic agriculture that is safe for consumers and eco-friendly. Therefore, the construction of peasant identities requires a paradigm shift, and livelihood adaptation, so that indigenous rice and peasants would have income and also preserve the ancestral cultures.

\section{Reference}

Chiengthong, Jamaree. (2018). Rural Society in Modern World. Faculty of Social Sciences, Chiang Mai University: 1-37

Dan Sai District of Agricultural Extension Office. (2015). Kok Sathon Subdistrict Basic Information Dan Sai District, Loei Province. Retrieved from http://dansai.loei.doae.go.th/ site/?p=619.

Kotchakot, Yingsak., Yamyim, Weeranuch. \& Sripuna, Suwaree. (2016). Geographic Information System Database Management of Rice Landraces in Ban Namyen, Koksathon Sub-District, Dansai District, Loei Province. Bangkok: The Thailand Research Fund.

Lefebvre, H. (1974). Production of Space. Retrieved May 6, 2017. Web site: https://monoskop.org/images/7/75/Lefebvre_Henri_The_Production_of_Space.pdf.

Mohd Yusri Ibrahim. (2017). The influence of communication practices on youth's Participation in volunteerism. Geografia-Malaysian Journal of Society and Space. 13(4): 80-92

Office of The National Economic and Social Development Council. (2019). The National Economic and Social Development Plan. Retrieved from https://www.nesdb.go.th/ main.php?filename=develop_issue.

Rice Department, Ministry of Agriculture and Cooperatives. (2012). The heritage of indigenous rice grain to honour His Majesty the King's $85^{\text {th }}$ Birthday. Bangkok: Rice Department Ministry of Agriculture and Cooperatives, 1-2.

Satsanguan, Ngampit. (2003). Rice culture in Thai society: Persistence and change. Bangkok: Chulalongkorn University Book Centre.

Sattaka, P. Pattaratuma, S. \& Attawipakpaisan, G. (2017). Agricultural extension services to foster production sustainability for food and cultural security of glutinous rice farmers in Vietnam. Kasetsart Journal of Social Sciences, 38(2): 74-80

Sattayanurak, Attachak. (2017). From rags to riches: From peasant to entrepreneur. Bangkok, Thailand: Mathichon: 17-23

Supanan, S (translate and compile). (2011). Space, time, identity and the creation of social meaning of Henri Lefebvre in Production of Space. Journal of Communication Arts, 29(3).

Slow Food Foundation for Biodiversity. (April, 2020). Bario Rice. Retrieved from https://www.fondazioneslowfood.com/en/ark-of-taste-slow-food/bario-rice/

Walliphodom, Srisak. (2013). Cultural ecology in the changes. Bankkok: Lek-Prapai Wiriyaphan Foundation: 9-19

Wittayapak, Chusak. (2018). Human ecology: Environmental study in dimention of social and culture. Chiang Mai: Research Administration Center, Chiang Mai University: 9-23 
Zimmerer, K. (2006). Cultural ecology: at the interface with political ecology - the new geographies of environmental conservation and globalization. Progress in Human Geography, 30: 63-78. 